\title{
Axial shrinkage-stress depends upon both C-factor and composite mass
}

\author{
David C. Watts, Julian D. Satterthwaite* \\ University of Manchester, School of Dentistry and Photon Science Institute, UK
}

\section{A R T I C L E I N F O}

\section{Article history:}

Received 29 June 2007

Received in revised form

15 August 2007

Accepted 16 August 2007

Keywords:

Polymerization shrinkage

Stress

C-factor

Resin-composite

\begin{abstract}
A B S T R A C T
Objectives. To measure and then mathematically model polymerization stress-dependence upon systematic variations of $\mathrm{C}$-factor (bonded/unbonded area ratio) for the Bioman instrument [1], recording stress by free cantilever-beam deflection; compliance $1.5 \mu \mathrm{m} / \mathrm{MPa}$.

Methods. A light-cured resin-composite (RZD103; Ivoclar) with $57 \%$ (v/v) $450 \mathrm{~nm}$ filler was studied. Facing surfaces: glass slab and steel rod-end, constituting the Bioman test chamber, being perpendicular to the measured axial stress-direction, were varied: (a) with roddiameters $(\phi)$, from 1 to $10 \mathrm{~mm}$ in $1 \mathrm{~mm}$ increments (with $0.8 \mathrm{~mm}$ gap height); and then (b) with gap heights $(h)$ in 16 steps from 0.05 to $1.50 \mathrm{~mm}$ (with $\phi=10 \mathrm{~mm}$ ). For each $h$ and $\phi$ combination, giving C-factors ranging from 0.6 to 100 , shrinkage-stress was recorded for $1 \mathrm{~h}$ from start of $40 \mathrm{~s}$ irradiation at $600 \mathrm{~mW} \mathrm{~cm}^{-2}$ for photo-polymerization at $23^{\circ} \mathrm{C}(n=3)$. Shrinkagestress $\left(\mathrm{S}_{\sigma}\right)$ was plotted directly as functions of $h, \phi$, and $C$ and also per unit composite mass, $\left(\mathrm{S}_{\sigma} \mathrm{g}^{-1}\right)$. ANOVA and Tukey's statistics were applied.

Results. Series A-diameter variation; with C-factor increasing from 0.6 to 6 , gave an exact exponential decrease in $S_{\sigma}$ from 45 to $8 \mathrm{MPa}$. Series B-height variation; with C-factor increasing from 3 to 100 , gave increasing $S_{\sigma}$ from 1 to $8 \mathrm{MPa}$. Since composite mass played an equally dominant role, plots of stress-variations per unit composite mass, $\left(\mathrm{S}_{\sigma} \mathrm{g}^{-1}\right)$ separated these effects, confirming progressive off-axial stress-relief with increasing $h$.

Significance. (i) Values of $h=0.8$ and $\phi=10 \mathrm{~mm}$, recommended [1] for Bioman use, were confirmed as appropriate. Every lab instrument for measuring $S_{\sigma}$ necessarily embodies specific $\mathrm{C}$-factors and compliance values in the instrument design. (ii) Configuration (C) factor is recognized as an important parameter affecting manifestation of shrinkage-stress within restorative cavities and luting gaps. However, the restorative mass must equally be considered when translating shrinkage-science into specific clinical recommendations.
\end{abstract}

(c) 2007 Academy of Dental Materials. Published by Elsevier Ltd. All rights reserved.

\section{Introduction}

The ratio of bonded to unbonded surfaces has been described as the configuration factor [C-factor], and further it has been suggested that only those restorations with a C-factor less than 1 will withstand shrinkage-stresses produced during the polymerization of resin-composites [2,3]. Contemporary bonding agents may resist the tensile force and maintain integrity (although this can cause cuspal movement and/or sensitivity), but failure of the bond and micro-gap formation remains likely in many situations. A number of studies have assessed the influence of $\mathrm{C}$-factor on marginal gap

\footnotetext{
* Corresponding author at: School of Dentistry, University of Manchester, Higher Cambridge Street, Manchester, M15 6FH, UK. Tel.: +44 161275 6621/6808; fax: +44 1612756710 .

E-mail address: julian.satterthwaite@manchester.ac.uk (J.D. Satterthwaite). 0109-5641/\$ - see front matter @ 2007 Academy of Dental Materials. Published by Elsevier Ltd. All rights reserved. doi:10.1016/j.dental.2007.08.007
} 
formation/microleakage $[4,5]$ and the shrinkage-stress developed under test conditions [6,7]. Discussion of the effect of C-factor should, however, always be related to a standardized mass of material undergoing shrinkage as was implicitly recognized by Watts et al. [1].

The characterization of polymerization shrinkage behavior and kinetics remains an important aspect in the development of restorative materials. A number of techniques have been employed for the investigation of shrinkage-stress kinetics, including use of Universal Testing Machines and also cantilever beams. The difficulty of comparing data from different studies has been commented on by Sakaguchi et al. [8]: not only are there problems with comparing data from different methods, but also when comparing the same method employed by different research laboratories. More information on the effect of variations in sample preparation will allow for greater insight into the validity of comparisons between studies. Additionally, as uniaxial stress is measured in all the currently employed techniques, variation in C-factor of the specimen will allow for testing of the assumed linear nature of shrinkage-stress vectors in such studies.

The aim of this study was to investigate the effect of variations in specimen size and configuration on shrinkage-stress. The specific objective was to study a model resin-composite using a cantilever beam method (Bioman apparatus) with variations in specimen height and diameter in order to:

compare the maximum shrinkage-stress values,

correlate the shrinkage-stress values to C-factor.

The null hypothesis was that variations in specimen configuration would have no effect on the shrinkage-stress.

\section{Materials and methods}

The resin-composite used for the investigation was RZD103, a visible-light-cured experimental formulation (Ivoclar Vivadent, Schaan, Liechtenstein) with 56.7 vol\% (76.4 wt\%) irregular filler of $450 \mathrm{~nm}$ size and monomer matrix comprising a mix of BisGMA, UDMA and TEGDMA.

\subsection{Shrinkage-stress measurement}

The Bioman instrument [1] was used for stress measurements. The lower face of a stainless-steel rod and the upper surface

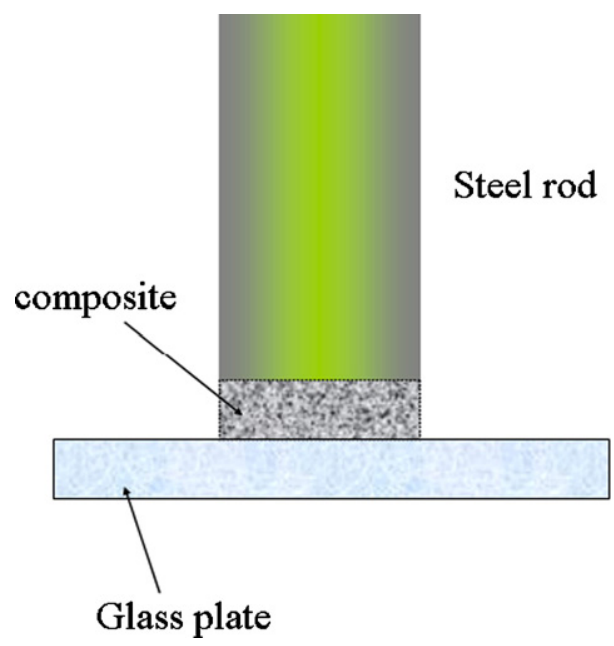

Fig. 1 - Representation of sample chamber and test surfaces.

of a glass slab form the surfaces of the specimen 'chamber' (Fig. 1). To systematically investigate effects of different configuration, two series of design-changes were studied, involving changes in: series A: specimen diameter; and series B: specimen height:

(A) For the assessment of the effect on shrinkage-stress with variation in specimen diameter $[\phi]$, the chamber height was set at $0.8 \mathrm{~mm}$ (as used for routine testing), and the standard stainless-steel rod was replaced with one of a series of machined rods with varying face diameter. Specimens of diameters varying from $1 \mathrm{~mm}$ to $10 \mathrm{~mm}$ (in $1 \mathrm{~mm}$ increments) were tested (Fig. 2).

(B) For the assessment of the effect on shrinkage-stress with variation in specimen height $[h]$, the standard stainlesssteel rod of $10 \mathrm{~mm}$ diameter was employed: alteration of the position of this steel rod within the integral clamp allowed the gap between the rod and glass to be adjusted. Specimens of heights varying from 0.05 to $1.5 \mathrm{~mm}$ were tested.

For all configurations tested, the surfaces of the test chamber (the glass slab and face of the stainless-steel rod) were lightly grit-blasted with $50 \mu \mathrm{m}$ alumina powder to promote bonding of the composite specimen. The amount of material required to form a specimen of the correct size without

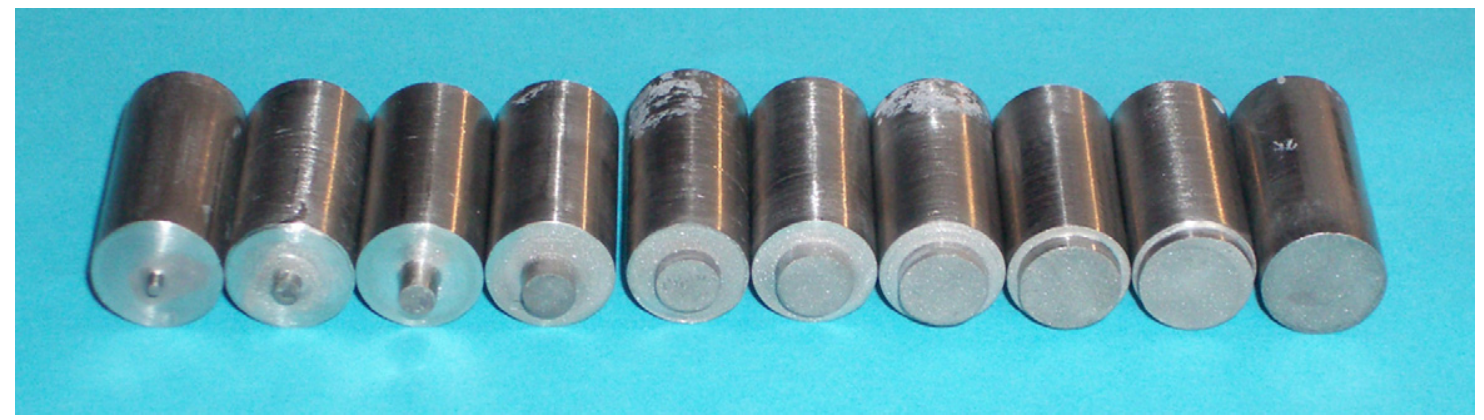

Fig. 2 - Stainless-steel test rods with varying face diameter: $1-10 \mathrm{~mm}$. 
Table 1 - Specimen configuration and mass: the configuration used routinely is shown in bold type

\begin{tabular}{lccc}
$\begin{array}{c}\text { Specimen } \\
\text { height }(\mathrm{mm})\end{array}$ & $\begin{array}{c}\text { Specimen } \\
\text { diameter }(\mathrm{mm})\end{array}$ & C-factor & $\begin{array}{c}\text { Mass of } \\
\text { material }(\mathrm{g})\end{array}$ \\
\hline 0.05 & 10 & 100.000 & 0.015 \\
0.1 & 10 & 50.000 & 0.025 \\
0.2 & 10 & 25.000 & 0.045 \\
0.3 & 10 & 16.667 & 0.060 \\
0.4 & 10 & 12.500 & 0.075 \\
0.5 & 10 & 10.000 & 0.090 \\
0.6 & 10 & 8.333 & 0.105 \\
0.7 & 10 & 7.143 & 0.125 \\
0.8 & 10 & 6.250 & 0.140 \\
0.9 & 10 & 5.556 & 0.145 \\
1.0 & 10 & 5.000 & 0.165 \\
1.1 & 10 & 4.545 & 0.185 \\
1.2 & 10 & 4.167 & 0.205 \\
1.3 & 10 & 3.846 & 0.220 \\
1.4 & 10 & 3.571 & 0.225 \\
1.5 & 10 & 3.333 & 0.240 \\
0.8 & 10 & 6.250 & 0.140 \\
0.8 & 9 & 5.625 & 0.110 \\
0.8 & 8 & 5.000 & 0.100 \\
0.8 & 7 & 4.375 & 0.090 \\
0.8 & 6 & 3.750 & 0.075 \\
0.8 & 5 & 3.125 & 0.060 \\
0.8 & 4 & 2.500 & 0.050 \\
0.8 & 1.875 & 0.030 \\
0.8 & 2 & 1.250 & 0.020 \\
0.8 & 2 & 0.625 & 0.010 \\
\hline & 1 & &
\end{tabular}

excess was determined through pilot testing, using samples of varying mass and direct measurement of the resultant disk.

For a circular rod of diameter $2 r$, and a specimen of a determined height $[h]$, the $\mathrm{C}$-factor $\left[C_{f}\right]$ is derived as follows:

$C_{\mathrm{f}}=\frac{2 \pi r^{2}}{2 \pi r h}=\frac{r}{h}=\frac{\phi}{2 h}$

The configurations tested, the C-factor and the amount (mass) of composite required to form the specimen in each case is given in Table 1 , with the usual configuration $(\phi=10 \mathrm{~mm}$ and $h=0.8 \mathrm{~mm}$ ) shown in bold type. For each configuration, three specimens were tested. After the specimen was positioned within the apparatus, it was left for a 1-min period for stabilization and relaxation of any internal stresses. Data for the calculation of stress development were recorded, commencing $20 \mathrm{~s}$ prior to irradiation each second for $60 \mathrm{~min}$. The three tests were conducted for each material at room temperature $\left(23^{\circ} \mathrm{C}\right)$. Irradiation was for $40 \mathrm{~s}$ from a halogen $(\mathrm{QTH})$ light cure unit at $600 \mathrm{~mW} / \mathrm{cm}^{2}$ (Optilux 501, Kerr, Orange, CA, USA). The light intensity was verified by an external radiometer (PM500A, Molectron Detector Inc., Portland, OR, USA).

\subsection{Data analysis}

For each test specimen, raw data were recorded as a text file. This file contained two columns of tab delimited data: time [t] and calibrated load signal [N]. These data were imported into SigmaPlot (SigmaPlot 2002 ver. 8, SPSS Inc., Illinois, USA) and uniaxial shrinkage-stress values calculated as previously described [1]. For each configuration tested, the maximum recorded shrinkage-stress of each of the three runs was recorded and the mean and standard deviation calculated. The data were entered into a statistical package (SPSS ver. 12.0.1, SPSS Inc., Illinois, USA) and analyzed with one-way ANOVA (independent variable C-factor, dependent variable maximum shrinkage-stress). Multiple post-hoc pairwise comparisons were performed using Tukey's test: statistical significance was assumed at $p=0.05$.

As specimen volumes were increased, greater specimen masses were present to exert a force, but also the increasing possibility of radial (non-axial) stress-relaxation was present. Hence, to disentangle these two effects, the shrinkage-stress data were normalized for variations in composite mass (shrinkage-stress per unit mass was calculated). Curve-fitting software (TableCurve 2D v4, SPSS Inc., Illinois, USA) was used to explore any relationship of shrinkage-stress per unit mass to $\mathrm{C}$-factor. The data for series A and B were imported into the software package and analyzed separately.

\section{Results}

The data obtained for changes in $\phi$ and $h$ were combined and the shrinkage-stress with the corresponding $\mathrm{C}$-factor is given in Table 2.

The lowest shrinkage-stress was seen with the thinnest specimen: $h=0.05 \mathrm{~mm}$ and $\phi=10 \mathrm{~mm}$ (1.22 MPa, SD0.09). The

\begin{tabular}{|c|c|c|c|c|}
\hline \multirow[t]{2}{*}{$h(\mathrm{~mm})$} & \multirow[t]{2}{*}{$\phi(\mathrm{mm})$} & \multirow[t]{2}{*}{ C-factor $=\phi / 2 h$} & \multicolumn{2}{|c|}{ Shrinkage-stress (MPa) } \\
\hline & & & Mean & SD \\
\hline 0.05 & 10 & 100.000 & 1.22 & 0.09 \\
\hline 0.1 & 10 & 50.000 & 1.94 & 0.10 \\
\hline 0.2 & 10 & 25.000 & 2.92 & 0.06 \\
\hline 0.3 & 10 & 16.667 & 3.49 & 0.10 \\
\hline 0.4 & 10 & 12.500 & 5.03 & 0.20 \\
\hline 0.5 & 10 & 10.000 & 5.45 & 0.10 \\
\hline 0.6 & 10 & 8.333 & 6.05 & 0.27 \\
\hline 0.7 & 10 & 7.143 & 6.74 & 0.35 \\
\hline 0.8 & 10 & 6.250 & 8.44 & 0.41 \\
\hline 0.9 & 10 & 5.556 & 7.79 & 0.21 \\
\hline 1.0 & 10 & 5.000 & 7.63 & 0.19 \\
\hline 1.1 & 10 & 4.545 & 7.83 & 0.68 \\
\hline 1.2 & 10 & 4.167 & 7.40 & 0.24 \\
\hline 1.3 & 10 & 3.846 & 7.27 & 0.73 \\
\hline 1.4 & 10 & 3.571 & 7.77 & 0.23 \\
\hline 1.5 & 10 & 3.333 & 7.61 & 0.45 \\
\hline 0.8 & 10 & 6.250 & 8.44 & 0.41 \\
\hline 0.8 & 9 & 5.625 & 8.06 & 0.20 \\
\hline 0.8 & 8 & 5.000 & 8.26 & 0.44 \\
\hline 0.8 & 7 & 4.375 & 12.27 & 2.05 \\
\hline 0.8 & 6 & 3.750 & 12.27 & 2.05 \\
\hline 0.8 & 5 & 3.125 & 17.56 & 0.57 \\
\hline 0.8 & 4 & 2.500 & 19.43 & 2.86 \\
\hline 0.8 & 3 & 1.875 & 25.61 & 2.20 \\
\hline 0.8 & 2 & 1.250 & 40.25 & 4.07 \\
\hline 0.8 & 1 & 0.625 & 45.34 & 6.86 \\
\hline
\end{tabular}




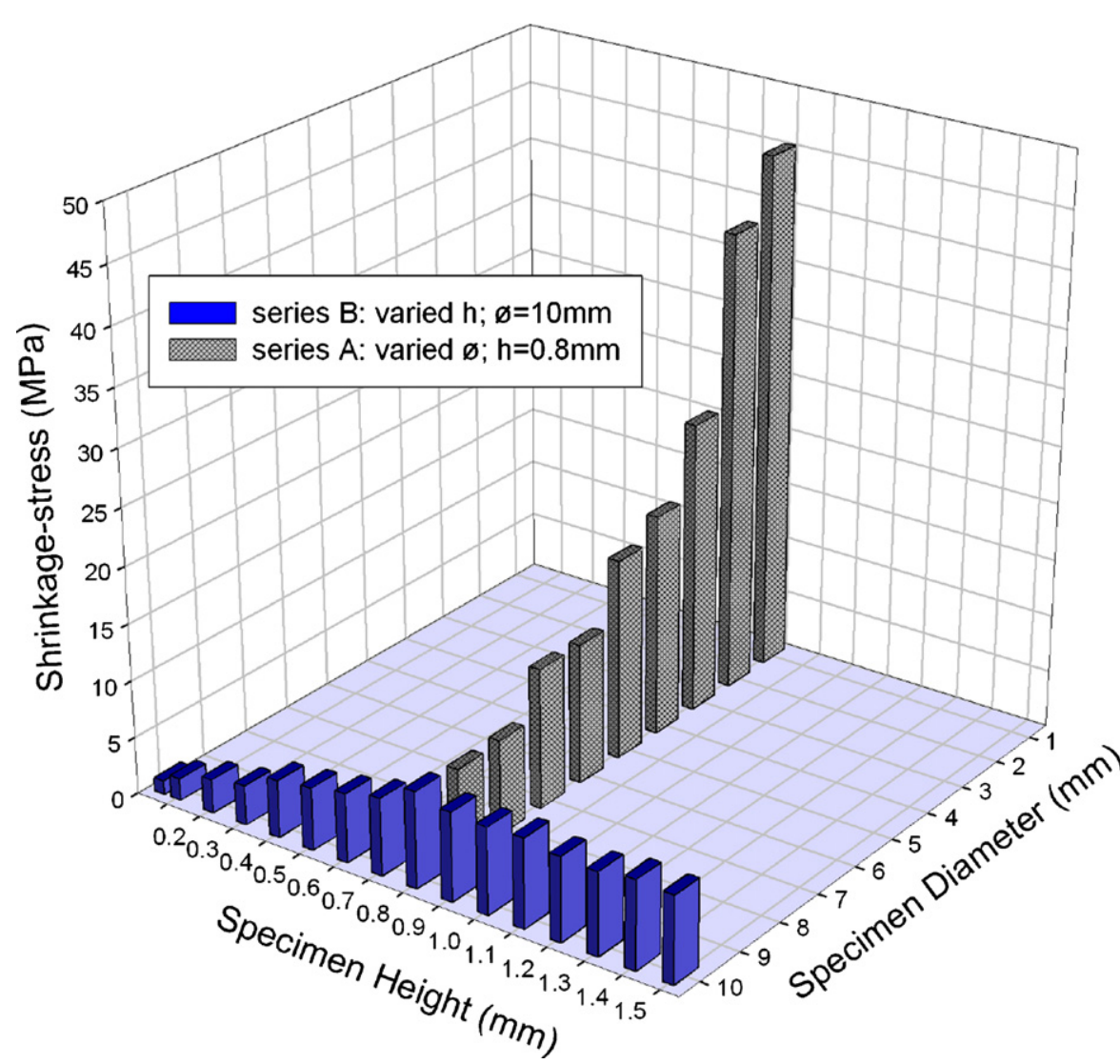

Fig. 3 - Shrinkage-stress against specimen height and diameter: in the normal measurement range proposed for specimen height and diameter, shrinkage-stress was invariant, compared to lower specimen heights or diameters.

highest shrinkage-stress was seen with the specimen with smallest diameter $-h=0.8 \mathrm{~mm}$ and $\phi=1 \mathrm{~mm}(45.34 \mathrm{MPa}, \mathrm{SD}$ 6.86). For series $A$, the shrinkage-stress generally decreased with increasing diameter, although this trend was not seen between $\phi=8$ and $10 \mathrm{~mm}$. For series B, the shrinkage-stress generally increased with an increase in specimen height, although between $h=0.9$ and $1.5 \mathrm{~mm}$, this trend was not seen, with little change in shrinkage-stress between these values. The change of shrinkage-stress with $\phi$ and $h$ is shown in Fig. 3.

The influence of C-factor on shrinkage-stress was statistically significant: this was the case where alterations in $\mathrm{C}$-factor were due to variations in the specimen height or in the diameter $(p<0.001)$. The general trend was for increased shrinkage-stress with a decrease in C-factor, although specimens with similar C-factors did not always have similar stress values: for example, a C-factor of 5 applies to $h=1 \mathrm{~mm}$, $\phi=10 \mathrm{~mm}$ and also $h=0.8 \mathrm{~mm}, \phi=8 \mathrm{~mm}$, and the stress values were $7.63 \mathrm{MPa}$ (SD 0.19) and $8.26 \mathrm{MPa}$ (SD 0.44), respectively. In cases where similar C-factors were observed, the series of tests at a constant height $(h=0.8 \mathrm{~mm})$ and varied diameter had higher values than the corresponding test at a constant diameter $(\phi=10 \mathrm{~mm})$ and varying height. The combined data is shown graphically in Fig. 4.

The data given in Table 3 show shrinkage-stress data per unit mass. The effects of variation in diameter (series A) and height (series B) on shrinkage-stress per unit mass are shown in Figs. 5 and 6 respectively. The influence of C-factor on shrinkage-stress per unit mass was statistically significant, whether alterations in C-factor were due to variations in the specimen diameter or in the height $(p<0.001)$. Tukey's posthoc test identified groups whose means were not statistically different. This is shown for C-factors where $\phi$ varies and $h=0.8 \mathrm{~mm}$, i.e. series A (Table 4), and also for C-factors where $h$ varies and $\phi=10 \mathrm{~mm}$, i.e. series B (Table 5): in both tables, configurations connected by bars are not statistically different.

For the data from series A (varied $\phi$ and constant $h$ ), the best-fit equation had a very strong relationship and high correlation coefficient $\left(r^{2}=0.9995\right)$. This relationship defining shrinkage-stress per unit mass $\left[S_{\sigma} g^{-1}\right]$ for a given $\mathrm{C}$-factor $\left[C_{\mathrm{f}}\right]$ (where $e$ (base of natural logarithm) $a, b$ and $k$ are constants) is given below:

$$
\begin{gathered}
\mathrm{S}_{\sigma} g^{-1}=a+b e^{-k C_{\mathrm{f}}} \\
a=83.70 \quad b=10460.41 \quad k=1.366
\end{gathered}
$$

For the data from series B (varied $h$ and constant $\phi$ ), the best-fit equation had a strong relationship and high correlation coefficient $\left(r^{2}=0.9263\right)$. The equation defining shrinkage-stress per unit mass $\left[\mathrm{S}_{\sigma} \mathrm{g}^{-1}\right]$ for a given $\mathrm{C}$-factor $\left[\mathrm{C}_{\mathrm{f}}\right]$ (where $e$ (base of natural logarithm) $a \& b$ are constants) is shown below:

$$
\begin{gathered}
S_{\sigma} g^{-1}=a+\frac{b}{\ln C_{\mathrm{f}}} \\
a=94.52 \quad b=-77.61
\end{gathered}
$$




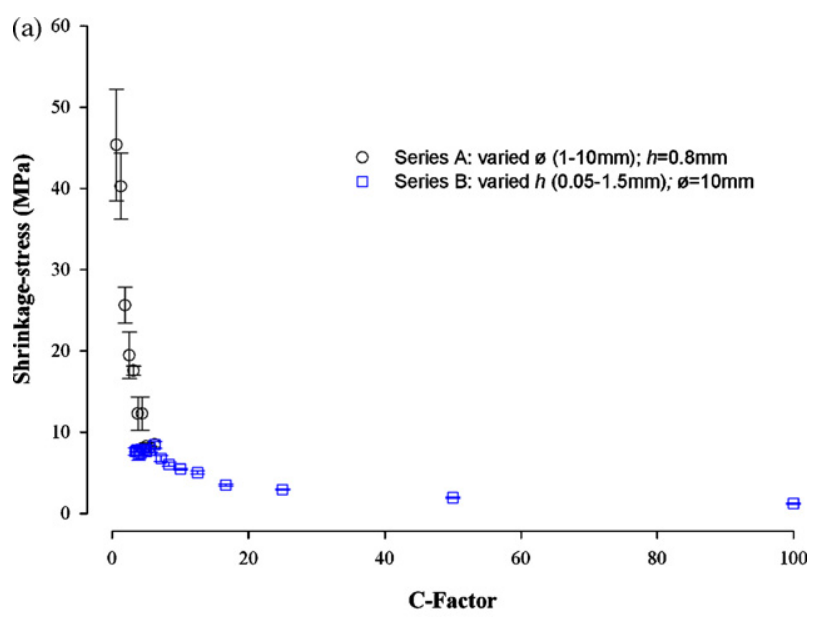

Table 3 - Maximum shrinkage-stress per unit mass: the configuration used routinely is shown in bold type

$h(\mathrm{~mm}) \quad \phi(\mathrm{mm}) \quad$ C-factor $=\phi / 2 h \quad$ Shrinkage-stress per

\begin{tabular}{lrrrr} 
& & & \multicolumn{2}{c}{ unit mass $\left(\mathrm{MPa} \mathrm{g}^{-1}\right)$} \\
\cline { 3 - 5 } & & & Mean & \multicolumn{1}{c}{$\mathrm{SD}$} \\
\hline 0.05 & 10 & 100.000 & 81.16 & 6.19 \\
0.1 & 10 & 50.000 & 77.39 & 3.83 \\
0.2 & 10 & 25.000 & 64.96 & 1.26 \\
0.3 & 10 & 16.667 & 58.22 & 1.65 \\
0.4 & 10 & 12.500 & 67.03 & 2.68 \\
0.5 & 10 & 10.000 & 60.55 & 1.16 \\
0.6 & 10 & 8.333 & 57.65 & 2.54 \\
0.7 & 10 & 7.143 & 53.94 & 2.80 \\
0.8 & 10 & 6.250 & 60.31 & 2.95 \\
0.9 & 10 & 5.556 & 53.73 & 1.47 \\
1.0 & 10 & 5.000 & 46.27 & 1.14 \\
1.1 & 10 & 4.545 & 42.32 & 3.68 \\
1.2 & 10 & 4.167 & 36.07 & 1.15 \\
1.3 & 10 & 3.846 & 33.06 & 3.34 \\
1.4 & 10 & 3.571 & 34.55 & 1.02 \\
1.5 & 10 & 3.333 & 31.72 & 1.87 \\
0.8 & 10 & 6.250 & 60.31 & 2.95 \\
0.8 & 9 & 5.625 & 73.23 & 1.86 \\
0.8 & 8 & 5.000 & 82.59 & 4.44 \\
0.8 & 7 & 4.375 & 136.30 & 22.82 \\
0.8 & 6 & 3.750 & 163.56 & 27.39 \\
0.8 & 5 & 3.125 & 292.58 & 9.52 \\
0.8 & 4 & 2.500 & 388.55 & 57.17 \\
0.8 & 3 & 1.875 & 853.64 & 73.46 \\
0.8 & 2 & 1.250 & 2012.38 & 203.42 \\
0.8 & 1 & 0.625 & 4533.60 & 686.28 \\
& 10 & & &
\end{tabular}

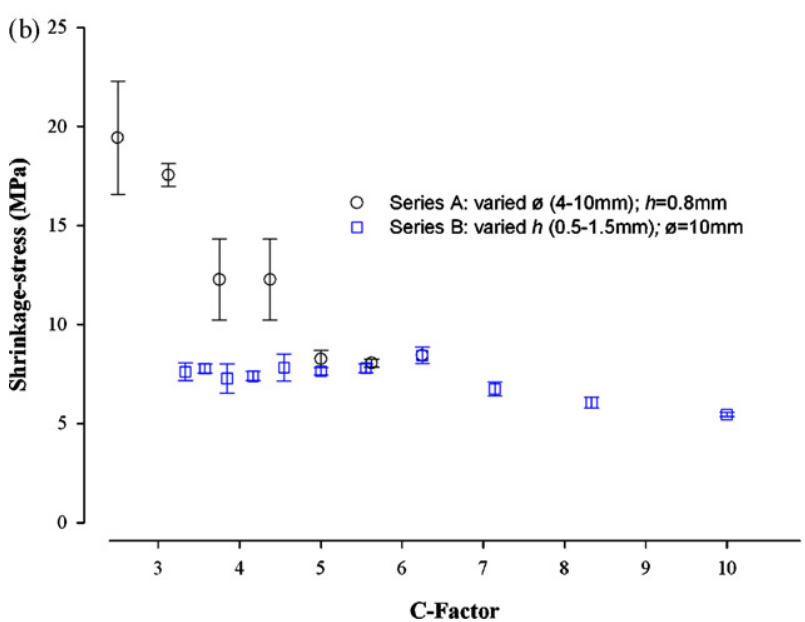

Fig. 4 - Shrinkage-stress against C-factor for series A and B: (a) all data; (b) detail of lower C-factors.

\section{Discussion}

Although shrinkage-stress values for the small specimens were relatively high, the actual force produced was relatively low. At these levels, the Bioman instrument retains a very high correlation and sensitivity to applied force, thus the large standard deviations seen with small specimens are likely to be due to the difficulty in consistent preparation of samples of the exact small size with these configurations.

Adding mass to increase height (and free surface) of composite leads to higher polymerization induced shrinkagestress values than with smaller samples due to the increased volume (or mass) of material, despite the reduction in Cfactor: this trend has been previously reported [1]. Other studies on thickness-effects on shrinkage-stress have mainly concentrated on very thin adhesive or composite specimens, as occur clinically in the cementation of inlays. Such studies [6,9] demonstrate a substantial variation in stress with height for thin specimens: in the current study, at greater thicknesses more representative of application of resin-composite for direct restoration, there was little variation in shrinkage-stress between $h=0.8$ and $1.5 \mathrm{~mm}$, so measurements made within this regimen represent a sta- ble invariance of outcome. Additionally, assessments in this range are less influenced by the effect of system compliance [10].

Other research utilizing a universal testing machine rather than a cantilever beam [11] has also demonstrated that

Table 4 - Series A (constant height, varied diameter): grouping of configurations with no statistically different mean uniaxial shrinkage-stress per unit mass

\begin{tabular}{|c|r|r|}
\hline \multirow{2}{*}{ C-factor } & \multicolumn{2}{|c|}{$\begin{array}{c}\text { Shrinkage-stress per } \\
\text { unit mass }\left(\mathbf{M P a ~}^{-1} \text { ) }\right.\end{array}$} \\
\cline { 2 - 3 } & Mean & \multicolumn{1}{c|}{ S.D. } \\
\hline 0.63 & 4533.60 & 686.28 \\
\hline 1.25 & 2012.38 & 203.42 \\
\hline 1.88 & 853.64 & 73.46 \\
\hline 2.50 & 388.55 & 57.17 \\
\hline 3.13 & 292.58 & 9.52 \\
\hline 3.75 & 163.56 & 27.39 \\
\hline 4.38 & 136.30 & 22.82 \\
\hline 5.00 & 82.59 & 4.44 \\
\hline 5.63 & 73.23 & 1.86 \\
\hline 6.25 & 60.31 & 2.95 \\
\hline
\end{tabular}

Configurations connected by bars are not significantly different. 

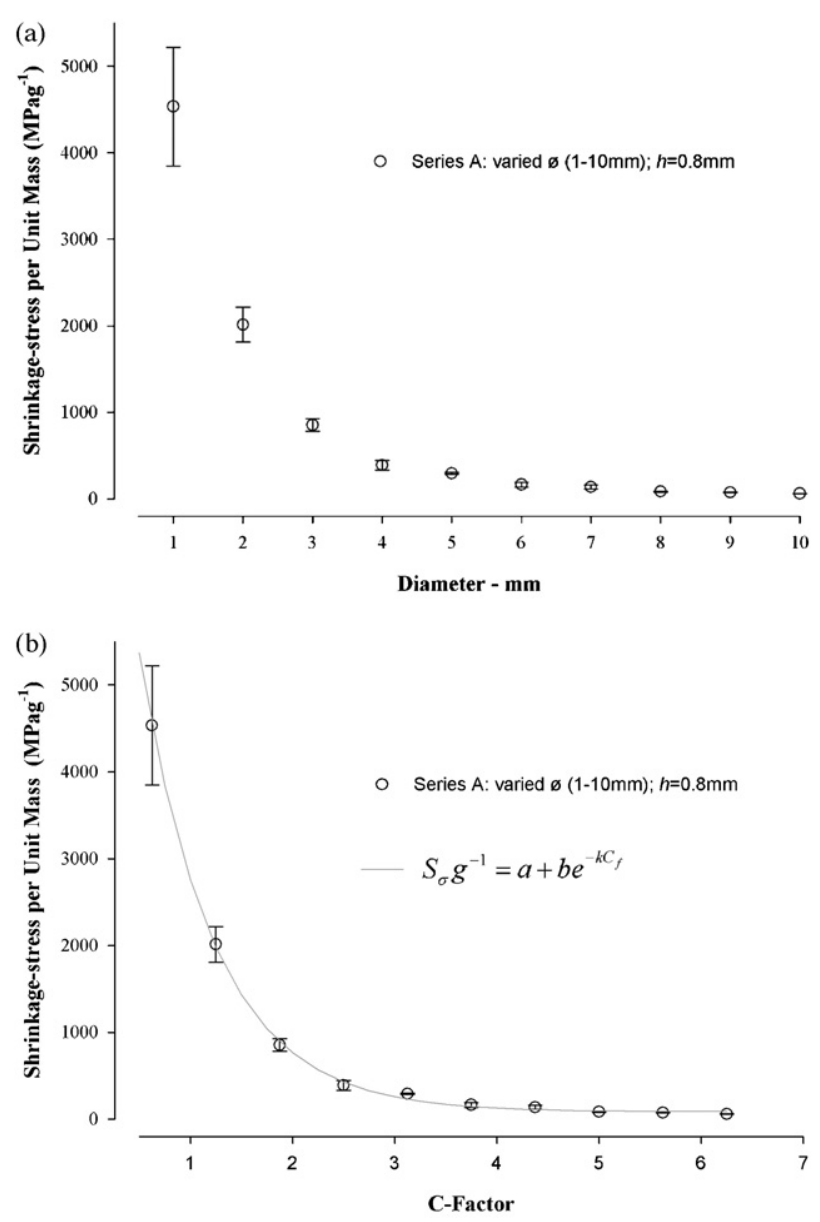

Fig. 5 - Series A graphs of shrinkage-stress per unit mass against: (a) diameter; (b) C-factor showing curve-fit.

shrinkage-force was directly related to composite volume and inversely related to $\mathrm{C}$-factor, even though for the cylindrical samples used, an increase in height increased both specimen volume and C-factor. However, their study only assessed a small range of configurations. In the present study, the uniaxial shrinkage-stress per unit mass decreased linearly with increasing height of the specimen $\left(r^{2}=0.9161\right)$ and hence with the corresponding decrease in $\mathrm{C}$-factor. This can be explained as being due to the increased free surface area of the specimen perimeter which, being free, allowed radial inward deformation (flow) during polymerization [2]: if the stress was entirely uniaxial, then the shrinkage-stress per unit mass would be constant, as shown schematically by the horizontal line in Fig. 6a. This trend for decreasing shrinkage-stress per unit volume (mass) with increasing height has also been shown by other workers using a cantilever beam of fixed compliance [10].

Increases in specimen diameter also resulted in less stress per unit mass, although little variation occurred between $\phi=8$ and $10 \mathrm{~mm}$, so measurements made within this regimen represent a stable invariance of outcome. This general trend for a high uniaxial shrinkage-stress value with the smallest diameter was inversely related to the $\mathrm{C}$-factor, and the high shrinkage-stress values with low $C_{\mathrm{f}}$ (where diameter is small)
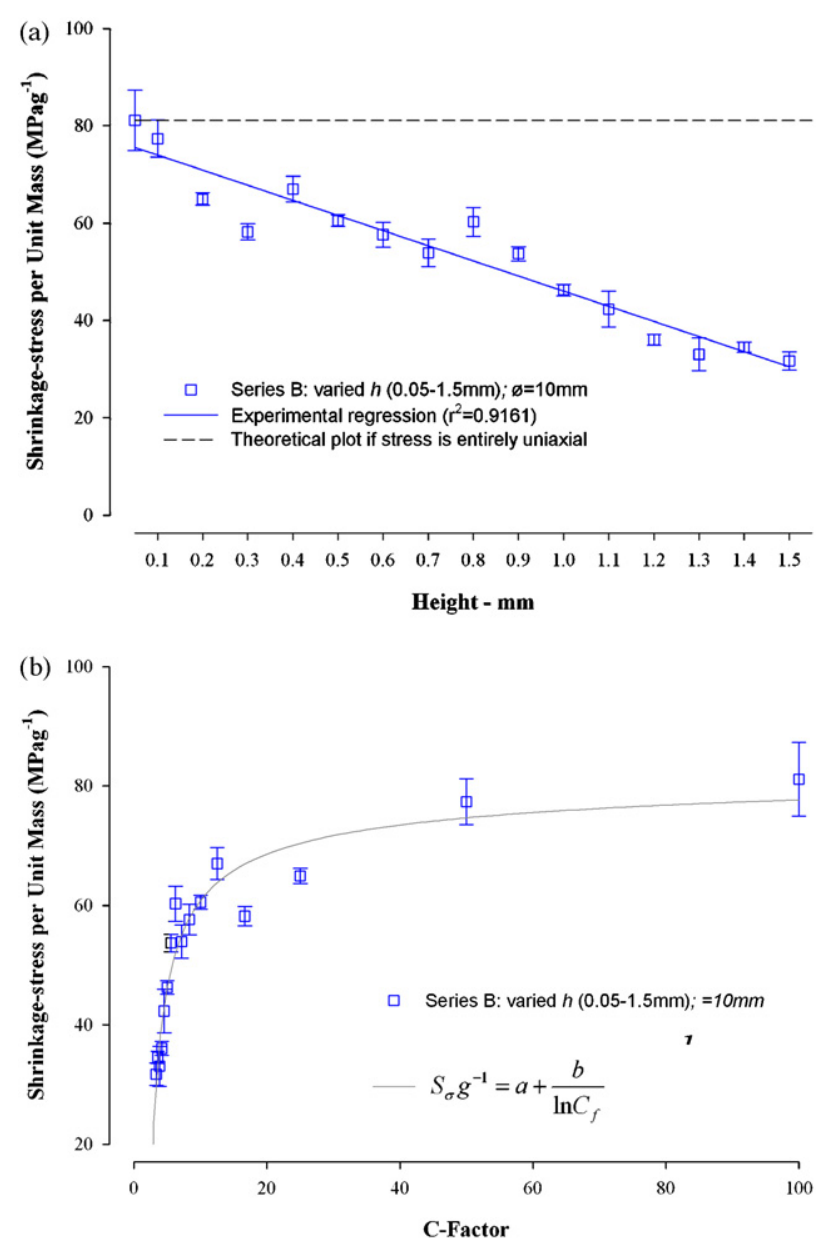

Fig. 6 - Series B graphs of shrinkage-stress per unit mass against: (a) height; (b) C-factor showing curve-fit.

is in apparent disagreement with previous studies and advice to maintain a low C-factor [3,12,13], although these studies employed a servo-controlled rigid system rather than a limited/fixed compliance system. Additionally microleakage due to shrinkage has been shown not to be correlated to C-factor, but is related to volume of the restoration [14]. Most studies assessing relationships of $\mathrm{C}$-factor to stress entail variation in specimen height [11] or variations in both height and diameter simultaneously [3], complicating the interpretation of the effect of each variable. A study assessing multiple configurations, including variations in diameter as well as height, in a system with limited compliance [15] produced findings strikingly similar to those due to alterations in specimen diameter found in the present study. However, Miguel and de la Macorra did not analyze the effects of variations in height or diameter independently.

If shrinkage-stress that is developed during polymerization cannot be relieved, then it is possible that multiple applications of small amounts of resin-composite may actually result in more stress-induced effects than the placement of a single larger increment of composite. Such a relationship has been demonstrated in numerical modelling [16], and assessment of restored cavities in bovine teeth in vitro has demonstrated that bulk placement of resin-composite does not lead to 
Table 5 - Series B (constant diameter, varied height): grouping of configurations with no statistically different mean uniaxial shrinkage-stress per unit mass

\begin{tabular}{|c|c|c|c|}
\hline & \multirow{2}{*}{ C-factor } & \multicolumn{2}{|c|}{$\begin{array}{l}\text { Shrinkage-stress per } \\
\text { unit mass }\left(\mathrm{MPa} \mathrm{g}^{-1}\right)\end{array}$} \\
\hline & & Mean & S.D. \\
\hline & 3.33 & 31.72 & 1.87 \\
\hline & 3.57 & 34.55 & 1.02 \\
\hline & 3.85 & 33.06 & 3.34 \\
\hline & 4.17 & 36.07 & 1.15 \\
\hline & 4.55 & 42.32 & 3.68 \\
\hline & 5.00 & 46.27 & 1.14 \\
\hline & 5.56 & 53.73 & 1.47 \\
\hline & 6.25 & 60.31 & 2.95 \\
\hline & 7.14 & 53.94 & 2.80 \\
\hline & 8.33 & 57.65 & 2.54 \\
\hline & 10.00 & 60.55 & 1.16 \\
\hline & 12.50 & 67.03 & 2.68 \\
\hline & 16.67 & 58.22 & 1.65 \\
\hline & 25.00 & 64.96 & 1.26 \\
\hline & 50.00 & 77.39 & 3.83 \\
\hline & 100.00 & 81.16 & 6.19 \\
\hline
\end{tabular}

Configurations connected by bars are not significantly different

more marginal gaps or lower bond strengths than incremental placement, even though the polymerization shrinkage-strain is increased [17]. Also, bulk placement has not been shown to cause significantly more cuspal movement than incremental placement [18]. However, these relationships are not straightforward, and the complex geometries of a tooth cavity may influence the shrinkage-stress kinetics in ways not identified in the present study. Additionally, care should be taken in attempting to extrapolate findings based upon a particular C-factor as the concept of configuration factor assumes rigid constraint; however, individual cavity/specimen geometry, cavity size and micro-structure of individual teeth will all lead to variation in compliance and limited constraint.

The C-factor had a significant affect on the uniaxial shrinkage-stress (and also uniaxial shrinkage-stress per unit mass) with variations in both $h$ and $\phi$. In cases where similar C-factors were observed, the series B tests at a constant height $(h=0.8 \mathrm{~mm})$ and varied diameter had higher values than the corresponding test (series A) at a constant diameter $(\phi=10 \mathrm{~mm})$ and varying height. Although the effect of $\mathrm{C}$-factor upon shrinkage-stress is clearly demonstrated, this suggests that the relationship is more complex than simply a ratio of bonded to unbonded surfaces. With the specimen configurations of a large height to diameter ratio (e.g. $h=1.5 \mathrm{~mm}$, $\phi=10 \mathrm{~mm} ; h=0.8 \mathrm{~mm}, \phi=1 \mathrm{~mm})$, the ability of the instrument to record all the shrinkage-stress was limited, and so the uniaxial stress measured was not fully representative of the total tri-axial stress magnitudes that are produced [19]. Nevertheless, it may be rebutted that the recorded axial stresses are those that are clinically relevant, as the major clinical implications relate to bond failure and microleakage [20], or cuspal movement [21], both of which are affected by axially orientated stresses at the bonded surfaces: internal stresses or stress-related radial flow at free surfaces are less, or nondeleterious to interfacial bond integrity.

\section{Conclusion}

For experiments assessing the shrinkage-stress kinetics of resin-composites, care should be taken in sample size and preparation. This is of particular concern for C-factors in the order of single figures. Within the range normally used for studies with the Bioman instrument $(\phi=10 \mathrm{~mm} ; \mathrm{h}=0.8 \mathrm{~mm}$; $C_{\mathrm{f}}=6.25$ ) small variations in height or diameter do not lead to significant differences, and measurements represent a stable invariance of outcome, where the material with respect to its formulation and/or cure condition (irradiance and temperature) and time is the variable. Adoption of this standardized configuration allows for convenient and reproducible specimen preparation and irradiation.

The null hypothesis that variations in specimen configuration would have no effect on the shrinkage-stress was rejected. Within the limitations of this study, it can be concluded that:

Configuration factor influences uniaxial shrinkage-stress.

The relationship of the specimen dimensions to shrinkagestress is a function not only of the C-factor (the ratio of bonded to unbonded surfaces), but also how the C-factor is created.

Servo-controlled rigid systems may not be best suited for studying the relationship of specimen dimensions to shrinkage-stress as a model for the situations encountered clinically in compliant tooth cavities.

Changes in diameter at constant height and changes in height at constant diameter show curvilinear relationships of uniaxial shrinkage-stress per unit mass that can be characterized mathematically.

\section{REF E R E N C E S}

[1] Watts DC, Marouf AS, Al-Hindi AM. Photo-polymerization shrinkage-stress kinetics in resin-composites: methods development. Dent Mater 2003;19:1-11.

[2] Davidson CL, de Gee AJ. Relaxation of polymerization contraction stresses by flow in dental composites. J Dent Res 1984;63:146-8.

[3] Feilzer AJ, De Gee AJ, Davidson CL. Setting stress in composite resin in relation to configuration of the restoration. J Dent Res 1987;66:1636-9.

[4] Choi KK, Ryu GJ, Choi SM, Lee MJ, Park SJ, Ferracane JL. Effects of cavity configuration on composite restoration. Oper Dent 2004;29:462-9.

[5] Uno S, Tanaka T, Inoue S, Sano H. The influence of configuration factors on cavity adaptation in compomer restorations. Dent Mater J 1999;18:19-31.

[6] Alster D, Feilzer AJ, de Gee AJ, Davidson CL. Polymerization contraction stress in thin resin composite layers as a function of layer thickness. Dent Mater 1997;13:146-50. 
[7] Feilzer AJ, De Gee AJ, Davidson CL. Increased wall-to-wall curing contraction in thin bonded resin layers. J Dent Res 1989;68:48-50.

[8] Sakaguchi RL, Wiltbank BD, Shah NC. Critical configuration analysis of four methods for measuring polymerization shrinkage strain of composites. Dent Mater 2004;20: 388-96.

[9] Choi KK, Condon JR, Ferracane JL. The effects of adhesive thickness on polymerization contraction stress of composite. J Dent Res 2000;79:812-7.

[10] Lee SH, Chang J, Ferracane J, Lee IB. Influence of instrument compliance and specimen thickness on the polymerization shrinkage stress measurement of light-cured composites. Dent Mater 2007;23:1093-100.

[11] Bouschlicher MR, Vargas MA, Boyer DB. Effect of composite type, light intensity, configuration factor and laser polymerization on polymerization contraction forces. Am J Dent 1997;10:88-96.

[12] Feilzer AJ, De Gee AJ, Davidson CL. Quantitative determination of stress reduction by flow in composite restorations. Dent Mater 1990;6:167-71.

[13] Davidson CL, Davidson-Kaban SS. Handling of mechanical stresses in composite restorations. Dent Update 1998;25:274-9.

[14] Braga RR, Boaro LC, Kuroe T, Azevedo CL, Singer JM. Influence of cavity dimensions and their derivatives (volume and 'C' factor) on shrinkage stress development and microleakage of composite restorations. Dent Mater 2006;22:818-23.

[15] Miguel A, de la Macorra JC. A predictive formula of the contraction stress in restorative and luting materials attending to free and adhered surfaces, volume and deformation. Dent Mater 2001;17:241-6.

[16] Versluis A, Douglas WH, Cross M, Sakaguchi RL. Does an incremental filling technique reduce polymerization shrinkage stresses? J Dent Res 1996;75:871-8.

[17] Loguercio AD, Reis A, Ballester RY. Polymerization shrinkage: effects of constraint and filling technique in composite restorations. Dent Mater 2004;20:236-43.

[18] Rees JS, Jagger DC, Williams DR, Brown G, Duguid W. A reappraisal of the incremental packing technique for light cured composite resins. J Oral Rehabil 2004;31:81-4.

[19] Laughlin GA, Williams JL, Eick JD. The influence of system compliance and sample geometry on composite polymerization shrinkage stress. J Biomed Mater Res 2002;63:671-8.

[20] Kemp-Scholte CM, Davidson CL. Marginal integrity related to bond strength and strain capacity of composite resin restorative systems. J Pros Dent 1990;64:658-64.

[21] Suliman AA, Boyer DB, Lakes RS. Cusp movement in premolars resulting from composite polymerization shrinkage. Dent Mater 1993;9:6-10. 